IFAS Extension

\title{
Vida Saludable: Cuidarse Desde la Cabeza a los Pies ${ }^{1}$
}

Jennifer Hillan ${ }^{2}$

Si usted padece de la diabetes, hay áreas de su cuerpo que requieren CENAFS cuidados especiales. Padecer de la diabetes puede causar complicaciones en algunas partes del cuerpo, tales como su piel, sus ojos, sus dientes, sus encías, y sus pies. Lea la siguiente información en como cuidar de su cuerpo desde la cabeza a los pies.

\section{La Piel}

Una piel saludable es la primera defensa contra toda infección. Sugerencias para una piel saludable:

$\checkmark$ Bañarse diariamente.

$\checkmark$ Secarse completamente con una toalla.

$\checkmark$ Prevenga la piel seca. Utilice jabón y loción suave. Durante el invierno también utilice un humidificador, si el aire está seco.

$\checkmark \quad$ No se aplique loción dentro de los dedos de los pies, en los pliegues de la piel o en las axilas. Utilice polvo para mantener estas áreas secas.

$\checkmark$ Cuide las heridas inmediatamente. Lávelas con jabón y agua y cúbralos con una cura. Solamente utilice ungüento o pomada que sea recomendada por su médico.

$\checkmark$ Visite inmediatamente su médico o proveedor de cuidado de salud si tiene una herida grande, si se ha quemado, o si ha contraído una infección.

$\checkmark$ Utilice protector solar.

$\checkmark$ Visite un dermatólogo (médico para piel) para resolver afecciones acerca de la piel.

\section{Ojos}

La retinopatía diabética (enfermedad de los ojos) es la complicación más común de la diabetes tipo 2 y es la mayor causa de ceguera en los Estados Unidos. El control de glucosa en la sangre y de la presión arterial puede ayudar a prevenir o demorar la retinopatía diabética.

Visite inmediatamente un oftalmólogo si tiene:

- La visión borrosa

- Dificultad leyendo señales o libros

- Presión en los ojos

- Manchas o partículas en sus ojos

- Los ojos rojos constantemente

Haga un examen anual para los ojos (con un oftalmólogo o un optómetra) para determinar el temprano desarrollo de las enfermedades de los ojos, y empezar así el tratamiento.

1. The English version of this Spanish document is Healthy Living: Taking Care from Head to Toe (FCS8821). Este documento, FCS8821-Span, pertenece a una serie del Departamento de Ciencias de la Familia, Juventud y Comunidad, Servicio de Extensión Cooperativo de la Florida, Instituto de Alimentos y Ciencias Agrícolas, Universidad de la Florida. Fecha de publicación: enero 2007. Favor de visitar el EDIS Web site en el http://edis.ifas.ufl.edu.

2. Jennifer Hillan, MSH, RD, LD/N, educadora/entrenadora, Departamento de Ciencias de la Familia, Juventud y Comunidad, Servicio de Extensión Cooperativo de la Florida, Instituto de Alimentos y Ciencias Agrícolas, Universidad de la Florida, Gainesville, FL 32611. Traducción por Jessica R. A. Caicedo, Universidad de la Florida.

\footnotetext{
The Institute of Food and Agricultural Sciences (IFAS) is an Equal Employment Opportunity - Affirmative Action Employer authorized to provide research, educational information and other services only to individuals and institutions that function without regard to race, creed, color, religion, age, disability, sex, sexual orientation, marital status, national origin, political opinions or affiliations. For information on obtaining other extension publications, contact your county Cooperative Extension Service office. Florida Cooperative Extension Service / Institute of Food and Agricultural Sciences / University of Florida / Larry R. Arrington, Dean
} 


\section{Los Dientes y Las Encías}

Las personas que sufren de diabetes tienen un alto riesgo de sufrir de enfermedades periodentales (las encías). Este puede llevar a perder dientes. Sugerencias para dientes y encías saludables:

$\checkmark$ Cepillarse los dientes dos veces al día.

$\checkmark$ Usar seda dental diariamente.

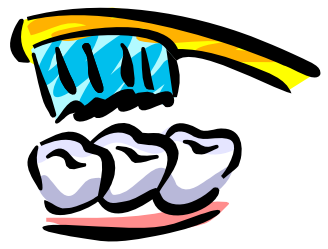

$\checkmark$ Visite su odontólogo cada seis meses

\section{Esté seguro en notificar a su odontólogo que usted padece de la diabetes.}

Visite su odontólogo si tiene indicaciones de la enfermedad periodental, por ejemplo, las encías que están rojas, inflamadas, sensibles o sangrando; mal aliento; o cambios en la manera en que los puentes y dentadura postiza ajustan.

\section{¿Sabía Usted Que?...}

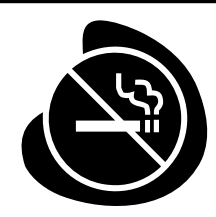

Fumar incrementa los riesgos de complicaciones en la diabetes.

Usted puede ayudar a prevenir las complicaciones de la diabetes si no fuma y mantiene su glucosa en la sangre en los niveles apropiados.

Consulte con su médico o proveedor del cuidado de la salud acerca del nivel apropiado de glucosa en la sangre.

\section{Los Pies}

Las llagas o ampollas en los pies pueden infectarse, causar incapacidad o incluso conducir a amputaciones. La buena noticia es que las lesiones en los pies pueden ser prevenidas.

Haga un examen anual con su médico o proveedor de cuidado de la salud y cuide de sus pies en casa. Aquel hay alunas instrucciones para el cuidado de sus pies:

Inspeccione diariamente sus pies para observar si usted tiene manchas rojas, heridas, inflamaciones o ampollas. Utilice un espejo para observar las plantas de los pies.

$\checkmark$ Lave diariamente y seque cuidadosamente sus pies, especialmente entre los dedos de los pies.

$\checkmark$ Mantenga la piel suave y saludable con una capa de loción sobre el empeine y la planta de los pies, pero no entre los dedos de los pies. Use una loción que no contenga alcohol.

$\checkmark$ Corte las uñas de los pies cuando sea necesario, córtelas rectamente y pula las orillas con una lima.

$\checkmark$ Calce zapatos y medias en vez caminar descalzo. Observe dentro de los zapatos antes de calzarlos.

$\checkmark$ Calce arrastraderas (slippers) antideslizantes en casa.

$\checkmark$ Calce medias limpias y zapatos que ajusten bien.

$\checkmark$ Proteja los pies del calor y el frío.

$\checkmark$ Para mantener la sangre fluyendo a través de los pies, levante los pies cuando esté sentado, doble los dedos de los pies y rote sus tobillos; no cruce sus piernas por largos periodos de tiempo.

$\checkmark$ Consulte con su médico o proveedor de cuidado de la salud acerca de llagas abiertas, infecciones o si un dedo de los pies ha enrojecido o está sensible (este puede ser una uña encarnada). 